\title{
Seizures with Alkaptonuria in Adults- The Untold
}

\author{
Nithish Mukunthan M. ${ }^{1}$, Santhosh V.2 , Balaji T. ${ }^{3}$, Suresh J.4 , Rajaram Manoharan T. ${ }^{5}$
}

\begin{abstract}
${ }^{1}$ Department of Anaesthesia and Critical Care, Preethi Super Speciality Hospitals, Madurai, Tamilnadu, India. 2Department of Anaesthesia and Critical Care, Preethi Super Speciality Hospitals, Madurai, Tamilnadu, India. ${ }^{3}$ Department of Anaesthesia and Critical Care, Preethi Super Speciality Hospitals, Madurai, Tamilnadu, India. ${ }^{4}$ Department of Anaesthesia and Critical Care, Preethi Super Speciality Hospitals, Madurai, Tamilnadu, India. ${ }_{5}^{5}$ Department of Anaesthesia and Critical Care, Preethi Super Speciality Hospitals, Madurai, Tamilnadu, India.
\end{abstract}

\section{INTRODUCTION}

Alkaptonuria, is a rare metabolic autosomal recessive disorder, which affects $1: 1,000,000$ people. It is also called endogenous ochronosis. Though it is mainly seen in children, in adults it usually presents after the age of $30 .{ }^{1}$ It arises from decreased activity of liver homogentisate 1,2-dioxygenase which leads to accumulation of homogentisic acid (HGA) and production of a melanin-like polymer which is deposited mainly in cartilaginous tissue, mucous, skin, bone surface, internal cardiac structures, as well as excreted in urine. ${ }^{2}$ The main presentation of alkaptonuria is valvular calcifications and osteoarthritis of spine, along with dark pigmentation of skin, cartilage, sclera and other connective tissues. It is diagnosed by a combination of clinical history, histopathological examination, and estimating the levels of homogentisic acid in urine. ${ }^{3}$

\section{PRESENTATION OF CASE}

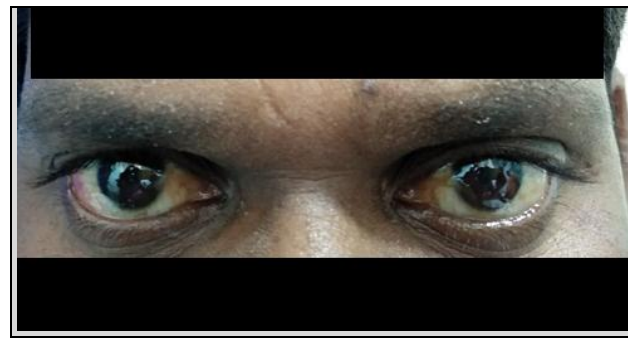

Figure 1.

Scleral Discolouration in Alkaptonuria

This is a rare case report of 40 years old male who presented with a complication of seizure with alkaptonuria. Consent form was obtained from the patient for the publication. The patient was a known hypertensive not on any medications presented to us with history of single episode of seizure on day of admission, manifested as unconsciousness episode with up rolling of eye balls. This seizure episode was preceded by 3 days history of high grade, intermittent fever with no other contributory history. In the ER patient was drowsy, arousable and haemodynamically stable. On clinical examination the patient had yellowish pigmentations in both eyes. On initial investigations the patient's Serum sodium was $115 \mathrm{meq} / \mathrm{L}$, Serum potassium was $2.5 \mathrm{meq} / \mathrm{L}$ while rest of the investigations were within normal limits. Patient was initially worked up for hyponatremia and was diagnosed to be the cause of seizures. Patient was slowly corrected with $3 \%$ normal saline infusion and put on anti-epileptic drugs. Serum osmolarity was $237 \mathrm{mosm} / \mathrm{Kg}$ with urine sodium 29 meq/L and urine osmolarity 163 mosm/Kg. Neurologist opinion was obtained and EEG done was normal, CT brain done was suggestive of diffuse cerebral oedema secondary to hyponatremia.
Corresponding Author: Dr. Nithish Mukunthan M., Department of Anaesthesia \& Critical Care, Preethi Super Speciality Hospitals, Melur Main Road, Uthangudi, Madurai-625020, Tamilnadu, India. E-mail: nithishchat@gmail.com

DOI: $10.14260 /$ jemds/2020/285

Financial or Other Competing Interests: None.

How to Cite This Article:

Mukunthan NM, Santhosh V, Balaji T, et al. Seizures with alkaptonuria in adults- the untold. J. Evolution Med. Dent. Sci. 2020;9(15):1313-1315, 10.14260/jemds/2020/285

Submission 04-02-2020, Peer Review 16-03-2020, Acceptance 22-03-2020, Published 13-04-2020.

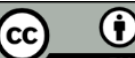




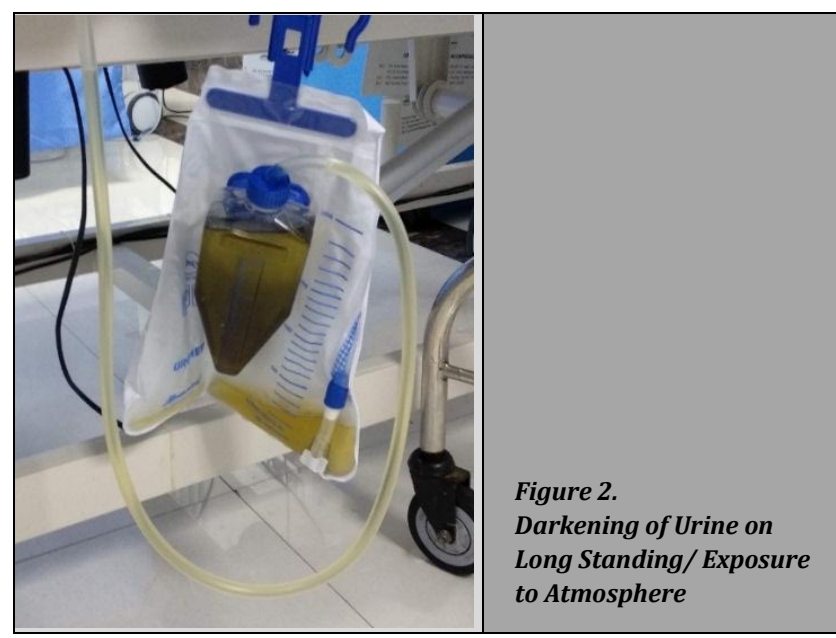

Patient was catheterized on first day of admission to monitor urine output. It was observed that on long standing the collected urine became dark in colour. Urine Homogentisic acid was sent which resulted positive. Patient was diagnosed with alkaptonuria. Patient was subsequently worked up for alkaptonuria. CT spine was done was suggestive of extensive premature degeneration with intra discal calcifications and vacuum phenomenon seen at most of thoraco lumbar vertebrae suggestive of ochronosis. Rest of the investigations done pertaining to alkaptonuria like ECHO, MRI brain were all normal. The patient did not show any signs of bone or cartilage involvement other than the radio graphic findings so was put on vitamin $\mathrm{C}$ supplementations and anti-epileptic drugs and discharged.

\section{DISCUSSION}

Sir Archibald Garrod in 1901 from London was the first one to describe about AKU as an inborn error of metabolism. AKU is an autosomal recessive genetic disorder. There is inborn error of metabolism of phenylalanine and tyrosine which manifests as inability to metabolize HGA. ${ }^{4}$ The HGA is part of phenylalanine and metabolic pathway. The deficiency of homogentisic acid oxidase enzyme leads to its accumulation, which polymerizes to a melanin like pigment having a high affinity for connective tissues like cartilage giving it an ochre colour, hence the name ochronosis. ${ }^{3}$

It is mainly diagnosed in children by identifying darkening of urine after long standing period in rest or in contact with environment or in babies by identifying blackened spots in diapers. But in adults, after fourth decade of life, it mainly manifests as osteoarthritis, manifesting as changes in eyes, wars, skin, CVS, renal and musculoskeletal system. ${ }^{5}$ Ocular manifestations are seen as brown scleral pigmentation. Dilated conjunctival vessels can be present and they supply the pigmented areas on the conjunctiva. ${ }^{6}$

The usual diagnosis is through clinical history and noting the changes in urine colouration when exposed to environment or air. Confirmation is by estimating the amount of HGA levels in urine. ${ }^{7}$

In our case it was a rare presentation of alkaptonuria with seizures. There has been instances were a case report of alkaptonuria manifesting as seizures has been reported in a 8 year old boy with EEG picking up classical epileptic activity.
However they could not establish a causal between both and concluded it to be a co-existing independent event. ${ }^{8}$

In addition to seizures the other significant finding in our case was the hyponatremia. There are case reports of alkaptonuria associated with renal tubular acidosis. ${ }^{9}$ Renal dysfunction is uncommon and late complication of alkaptonuria, that manifests as decreased renal excretion and increased parenchymal concentration of HGA.10,11 Renal biopsy will show chronic tubulointerstitial disorder with ochronotic coarse granular pigment deposition, along with occasional glomerular sclerosis and connective tissue destruction. ${ }^{12,13}$

Though we don't have evidences to prove renal tubular acidosis in our patient as he was not willing for renal biopsy, so with the presence of hypokalemia and hyponatremia we hypothesize that the patient would have had distal renal tubular acidosis as renal tubular secretion is important for the elimination of HGA, which if impaired leads to both distal RTA and alkaptonuria.

Medical therapy reduces the rate of deposition of pigment. Reduction of phenylalanine and tyrosine reduces HGA excretion. Vitamin C, in a dose of $1 \mathrm{~g} /$ day, is recommended for older children and adults. Ascorbic acid being an antioxidant helps in slowing the process of conversion of homogentisate which is deposited as polymerized material in cartilaginous tissues. $^{14,15}$ Use of nitisinone, 4-hydroxyphenylpyruvate dioxygenase enzyme inhibitor, which inhibits formation of HGA and accumulates the upstream precursor tyrosine has been reported but its use is limited. ${ }^{16}$ In our case as the patient was asymptomatic in all other aspects and improved clinically we discharged the patient with Vitamin C tablet supplementations and anti-epileptic drugs.

\section{CONCLUSIONS}

Though it is still unclear, and not enough reports and evidences are available to establish a causal relationship between alkaptonuria and seizures, we hypothesize based on all the previously available case reports that alkaptonuria has, induced hyponatremia, secondary to distal RTA which in turn has caused seizures in our patient.

\section{REFERENCES}

[1] Aquaron R. Alkaptonuria: a very rare metabolic disorder. Indian J Biochem Biophys 2013;50(5):339-44.

[2] Ranganath LR, Jarvis JC, Gallagher JA. Recent advances in management of alkaptonuria (invited review; best practice article). J Clin Pathol 2013;66(5):367-73.

[3] Thomas M, Jebaraj JI, Thomas M, et al. Acral pigmentation in alkaptonuria resembling degenerative collagenous plaques of the hands: a report of five cases. J Am Acad Dermatol 2011;65(2):e45-6.

[4] Garrod AE. The incidence of alkaptonuria: a study in chemical individuality 1902 [classical article]. Yale J Biol Med 2002;75(4):221-31.

[5] Pettit SJ, Fisher M, Gallagher JA, et al. Cardiovascular manifestations of alkaptonuria. J Inherit Metab Dis 2011;34(6):1177-81. 
[6] Hackethal U, Busse H, Seitz HM, et al. Vermiform conjunctival structures. Ophthalmologe 2004;101(6):626-8.

[7] Ramos-e-Silva M, Azevedo-e-Silva MC, Carneiro SC. Hair, nail and pigment changes in major systemic disease. Clin Dermatol 2008;26(3):296-305.

[8] Bhaskar PA, Neelakandan B. Alkaptonuria with seizures. J Neurol Neurosurg Psychiatry 1983;46(1):98.

[9] Nickavar A, Azar MR. Alkaptonuria, a new association of distal renal tubular acidosis. Saudi J Kidney Dis Transpl 2018;29(4):997-9.

[10] Faria B, Vidinha J, Pêgo C, et al. Impact of chronic kidney disease on the natural history of alkaptonuria. Clin Kidney J 2012;5(4):352-5.

[11] Venkataseshan VS, Chandra B, Graziano V, et al. Alkaptonuria and renal failure: a case report and review of the literature. Mod Pathol 1992;5(4):464-71.
[12] Wyre HW. Alkaptonuria with extensive ochronosis. Arch Dermatol 1979;115:461-3.

[13] Kazancioglu R, Taylan I, Aksak F, et al. Alkaptonuria and renal failure: a case report. J Nephrol 2004;17(3):441-5.

[14] Anikster Y, Nyhan WL, Gahl WA. NTBC and alkaptonuria. Am J Hum Genet 1998;63(3):920-1.

[15] Mayatepek E, Kallas K, Anninos A, et al. Effects of ascorbic acid and low-protein diet in alkaptonuria. Eur J Pediatr 1998;157(10):867-8.

[16] Hughes AT, Milan AM, Christensen P, et al. Urine homogentisic acid and tyrosine: simultaneous analysis by liquid chromatography tandem mass spectrometry. J Chromatogr B Analyt Technol Biomed Life Sci 2014;963:106-12. 